University of New Hampshire

University of New Hampshire Scholars' Repository

3-1-2002

\title{
An Experimental and Analytical Approach to Understanding the Dynamic Leaching from Municipal Solid Waste Combustion Residue
}

\author{
Kevin H. Gardner \\ University of New Hampshire, kevin.gardner@unh.edu \\ Thomas L. Theis \\ Center for Environmental Management \\ Ramesh lyer
}

Follow this and additional works at: https://scholars.unh.edu/civeng_facpub

Part of the Civil and Environmental Engineering Commons

\section{Recommended Citation}

Gardner, K.H., T.L. Theis, R. lyer, "An Experimental and Analytical Approach to Understanding the Dynamic Leaching from Municipal Solid Waste Combustion Residue," Environmental Engineering Science 19(2), 89-100 (2002).

This Article is brought to you for free and open access by the Civil and Environmental Engineering at University of New Hampshire Scholars' Repository. It has been accepted for inclusion in Civil and Environmental Engineering Scholarship by an authorized administrator of University of New Hampshire Scholars' Repository. For more information, please contact Scholarly.Communication@unh.edu. 


\title{
An Experimental and Analytical Approach to Understanding the Dynamic Leaching from Municipal Solid Waste Combustion Residue
}

\author{
Kevin H. Gardner, ${ }^{1, *}$ Thomas L. Theis, ${ }^{2, \dagger}$ and Ramesh Iyer \\ ${ }^{1}$ Recycled Materials Resource Center \\ Department of Civil Engineering \\ University of New Hampshire \\ Durham, NH 03824 \\ ${ }^{2}$ Center for Environmental Management \\ Clarkson University \\ Potsdam, NY 13699-5715
}

\begin{abstract}
This paper describes an experimental technique involving the use of small columns for generating significant quantities of leachate data from municipal solid waste (MSW) solid residues within a relatively short amount of time. Data analysis using the discretized mass balance equations descriptive of the system results in best estimates of governing transport parameters that can, in turn, be used to predict the long-term release of leachable components ( $\mathrm{As}, \mathrm{Cd}, \mathrm{Cu}, \mathrm{Fe}, \mathrm{Ni}, \mathrm{Pb}, \mathrm{Zn}, \mathrm{Ca}, \mathrm{Mg}, \mathrm{Na}, \mathrm{K}, \mathrm{Cl}, \mathrm{SO}_{4}$ ) from the solid matrix. Results indicate that both chemical solubility and physical transport are important factors affecting the flux of contaminants from the solid to the solution phase.
\end{abstract}

Key words: experimental technique; leachate data; municipal solid waste solid residue

\section{INTRODUCTION}

$\mathbf{T}$ He COMbustion OF MUNICIPAL SOLID WASTE produces a significant volume of residue that must be managed in an environmentally and economically responsible manner. In the United States, approximately $17 \%$ of municipal solid waste is incinerated, resulting in some 7 million tons of ash requiring management, the majority (94\%) of which is landfilled, while 6\% is used beneficially (USEPA, 1998; Wiles and Shepherd, 1999). In the
European Union, there is a focus on understanding the leaching behavior of ashes in natural environments, rather than in landfills, as up to $90 \%$ of ash is reused in a beneficial manner in some countries (Wiles and Shepherd, 1999). Along with the increasing interest in beneficial use (in the United States and elsewhere) of many types of industrial and municipal byproducts is concomitant attention to more accurate assessment and prediction of long-term release of chronically harmful contaminants.

Significant progress has been made in the last decade

*Corresponding author: Recycled Materials Resource Center, University of New Hampshire, Durham, NH 03824-4597.Phone: 603-862-4334; Fax: 603-862-3957;E-mail: kevin.gardner@unhedu

$\dagger$ Present address: Institute for Environmental Science and Policy, University of Illinois at Chicago, Chicago, IL. 
in understanding and modeling the release of elements from residues in static systems (see Chandler et al., 1997, for a thorough review). For most elemental contaminants, equilibrium solubility, combined with complexation and adsorption reactions, has been able to describe release behavior fairly well. For example, Van der Hoek and Comans (1996) and Meima and Comans (1998) demonstrate that modeling the release of $\mathrm{As}, \mathrm{Se}, \mathrm{Mo}, \mathrm{Pb}$, and $\mathrm{Cu}$ in batch equilibrium experiments is improved by including sorption to a generic hydrous ferric oxide. Meima et al. (1999) demonstrated that copper release is strongly a function of dissolved organic carbon (DOC) in the leachate, where $95-100 \%$ of dissolved $\mathrm{Cu}$ is complexed with DOC.

There has been relatively less focus on the significance of the type of leaching test used to understand the leaching behavior of these residues in the natural environment, and perhaps as a result, less harmonization of the chemical and physical aspects that control the leaching process. Kosson et al. (1996) present an approach that can be used to estimate contaminant release using two different assumptions: one in which equilibrium chemical relationships control solute concentrations, the other where diffusion controls contaminant release. Fruchter $e t$ al. (1990) identify a number of solubility-controlling minerals from field-scale lysimeter tests, but do not consider physical transport processes that may govern or influence leachate quality. Similarly, Buccholz and Landsberger (1995) and Chichester and Landsberger (1996) quantify the release of some 50 elements in lab-scale sequential extraction procedures and column experiments, respectively.

The purpose of this manuscript is to communicate a new type of dynamic leaching test, termed "minicolumn," for the rapid and inexpensive collection of solute release data. Furthermore, the test is coupled with a numerical solute release model capable of accounting for chemical relationships (for solid-phase control of solute release) and physical transport phenomena simultaneously. The model was developed to estimate those parameters that govern the composition of leachates from ash materials, parameters that may subsequently be used in the assessment of long-term environmental impact. A unique approach is used in which the experimental solute release data from column experiments serves as the initial condition for the leachate model, which is then used to estimate the governing coefficients.

\section{MATERIALS AND METHODS}

\section{Sample collection}

Fly ash was collected from a 50-ton/day starved-air MSW incineration facility, and was collected prior to the quench tank. A 24-h composite sample was taken from this facility, and was prepared by drying at $103^{\circ} \mathrm{C}$ and homogenization prior to all analyses and experiments. Additional characterization of the ash has been presented elsewhere (Gardner, 1991).

\section{Chemical analysis}

Trace elements (As, $\mathrm{Cd}, \mathrm{Cu}, \mathrm{Fe}, \mathrm{Ni}, \mathrm{Pb}, \mathrm{Zn}$ ) were analyzed using atomic absorption spectrophotometry (PerkinElmer, Shelton, CT; Zeeman/5000 system). Both flame and flameless methods were used, with matrix modification as specified by the manufacturer. Major Ions $(\mathrm{Ca}, \mathrm{Mg}$, $\mathrm{Na}, \mathrm{K}, \mathrm{Cl}, \mathrm{SO}_{4}$ ) were analyzed by ion chromatography interfaced with a Dionex 4000i/4270 integrator. Alkalinity was determined by titration with $0.01 \mathrm{~N} \mathrm{HCl}$.

\section{Physical analysis}

Physical characterization of the ash material was accomplished by BET $\mathrm{N}_{2}$ adsorption for surface area and $\mathrm{Hg}$ intrusion porosimetry to characterize pore size distribution. Loss on ignition was measured by heating a dried sample to $550^{\circ} \mathrm{C}$ for one hour. Physical characterization of the ash material is provided in Table 1.

\section{Experimental apparatus}

The minicolumns used in this research had an inside diameter of $1.5 \mathrm{~cm}$ and a variable length up to $5 \mathrm{~cm}$, yielding a maximum sample volume of approximately $8.8 \mathrm{~cm}^{3}$. Although this is a relatively small sample size, given a huge quantity of ash being more or less continuously produced in any one given incinerator, it is not clear that a large column is any more representative than a small one. The primary concern with small columns is when there is a large amount of heterogeneity in individual particle properties (e.g., one large particle that, in a small sample, skews the results). In the case of this research, the samples were homogenized fly ashes of relatively uniform, small particle size. Ash was retained in the column by $0.45-\mu \mathrm{m}$ cellulose acetate filters backed by glass fiber filters. Ash was placed in the columns dry, and tamped into place uniformly using a cylindrical tool in a single lift. Effluent from the column passed through a small-volume flow-through cell for measurement of $\mathrm{pH}$. Column effluent was collected in a fraction collector in 20 -mL volumes (approximately 7 pore volumes, which

Table 1. Physical characteristics of ash.

\begin{tabular}{ll} 
Surface area $\left(\mathrm{m}^{2} / \mathrm{g}\right)$ & 2.0 \\
Bulk density $\left(\mathrm{g} / \mathrm{cm}^{3}\right)$ & 1.7 \\
Total pore volume $\left(\mathrm{cm}^{3} / \mathrm{g}\right)$ & 0.24 \\
Loss on ignition $(\%)$ & 2.6 \\
\hline
\end{tabular}


was the minimum volume required for all major ion and trace metal analyses). The samples from the fraction collector were split; one part was preserved with $0.2 \% \mathrm{HNO}_{3}$ for analysis of metals, and one was left unpreserved for major ion analysis. All samples were stored at $4{ }^{\circ} \mathrm{C}$ for subsequent analysis.

Column experiments were conducted at flow rates of $0.1,0.5,2$, and $6 \mathrm{~mL} / \mathrm{min}$. The duration of these experiments varied between 68 and 290 h. Tracer experiments indicated that the columns, at all flow rates, exhibited negligible longitudinal dispersion.

\section{RESULTS AND DISCUSSION}

\section{Contaminant fluxes}

The purpose of using the minicolumn reactor design was to observe changes in leachate composition with time or quantity of leachate produced, as well as to enable the manipulation of the flow rate to assist in determining the mass transfer processes that are responsible for the observed contaminant releases. Figure 1 shows the release of the major anions, cations, and trace elements leached in the column at a flow rate of $2 \mathrm{~mL} / \mathrm{min}$. The magnitude of change of any given ion or trace element is significant, decreasing by several orders of magnitude within about a thousand pore volumes. At the same time, the $\mathrm{pH}$ of the leachate increases significantly from 4.2 to above 10 [see Fig. 1(c)]. This is assumed to be due to the initial leaching of acidic aerosols such as $\mathrm{HCl}$ and $\mathrm{H}_{2} \mathrm{SO}_{4}$ that condense on the surface of ash particles during cooling, covering a more chemically basic mineral structure.

In addition to the change of individual element concentrations with time, the solution composition also changes. For example, calcium is the dominant cation at early times until about 5,000 pore volumes when the solution becomes relatively enriched in potassium. At later times potassium, although at relatively low concentrations, is the dominant cation by an order of magnitude over calcium and sodium. Similarly, chloride begins at concentrations approximately five times that of sulfate, but at later times sulfate is the dominant anion by a factor of 10. This suggests nonuniform distributions of various chemical components within the ash particles and perhaps leaching rates controlled by different processes.

Figures 2 and 3 show results similar to those displayed in Fig. 1 for experiments conducted at flow rates of 0.5 $\mathrm{mL} / \mathrm{min}$ and $0.1 \mathrm{~mL} / \mathrm{min}$, respectively. As the flow rate is decreased, most of the major ions show an increase in concentration for the duration of the column experiments, with the exception of calcium and sulfate. It appears that the transport of $\mathrm{Na}, \mathrm{K}$, and $\mathrm{Cl}$ is limited by the contact time with the solution, suggesting that diffusive transport from within the ash particles is rate limiting. Chloride, for example, levels off at about $0.5 \mathrm{ppm}$ at a flow rate of $2 \mathrm{~mL} / \mathrm{min}$, at about $9 \mathrm{ppm}$ at a flow rate of $0.5 \mathrm{~mL} / \mathrm{min}$, and at about $60 \mathrm{ppm}$ at a flow rate of $0.1 \mathrm{~mL} / \mathrm{min}$. Magnesium also obeys this behavior, being below the detection limit at the highest flow rate, and demonstrating increasing concentration with decreasing flow rate.

In contrast to major ionic components, trace elements show similar concentrations at all three flow rates. One notable exception is the higher initial zinc concentrations at the lower flow rates. This difference in concentration, however, ceases to exist much beyond the first few data points. The lack of variation of trace element concentration with flow rate suggests the solubility of solid phases may control the release of these solutes.

\section{Solubility controls}

The chemical composition of the solutions was investigated using the equilibrium speciation program $\mathrm{HY}$ DRAQL (Papelis et al., 1998), which was employed as a tool to generate ion activities in the leachate. The results of activity determinations yield data as shown in Fig. 4(a). The $\log$ of $\mathrm{Pb}^{+2}$ activity is plotted against $\mathrm{p}\left(\mathrm{SO}_{4}{ }^{-2}\right)$, where $\left(\mathrm{SO}_{4}{ }^{-2}\right)$ represents sulfate activity. The solid lines represent the range of solubility values found in the literature for $\mathrm{PbSO}_{4(\mathrm{~s})}$ (National Institute of Standards and Technology, 1995). It should be kept in mind that each data point in Fig. 4(a) corresponds to a specific sampling time and, hence, $\mathrm{pH}$. The sulfate values display a simple decay-type curve (see Fig. 3), so that the timeline in Fig. 4(a) is left to right, that is, decreasing sulfate corresponds to increasing time. It appears that the first data point falls within the solubility envelope for $\mathrm{PbSO}_{4(\mathrm{~s})}$, and after the first three data points all subsequent values fall well below the solubility limit. In comparison, Fig. 4(b) shows $\log \left(\mathrm{Pb}^{+2}\right)$ vs. $\mathrm{pH}$, and is compared with the theoretical solubility of $\mathrm{Pb}(\mathrm{OH})_{2(\mathrm{~s})}$. The first three data points, those apparently in equilibrium with lead sulfate, are undersaturated with respect to lead hydroxide due to the low $\mathrm{pH}$ during early times. As the $\mathrm{pH}$ rises and $\mathrm{SO}_{4}{ }^{-2}$ activity decreases, it appears that lead activity in solution is controlled by the solubility of lead hydroxide. It is also interesting to note the time sequencing of the data points in Fig. 4(b). As shown in Fig. 3 , the $\mathrm{pH}$ starts at a low value, reaches a maximum, and subsequently drops toward neutrality. The data points in Fig. 4(b), then, begin at the far left, proceed to a maximum $\mathrm{pH}$, and return toward the left, while following the $\mathrm{Pb}(\mathrm{OH})_{2(\mathrm{~s})}$ solubility line. At the peak $\mathrm{pH}$ values carbonate activity reaches a maximum, and the lead activity may be temporarily controlled by the solubility of $\mathrm{PbCO}_{3(\mathrm{~s})}$. Lead activity does not display simple decay- 
a

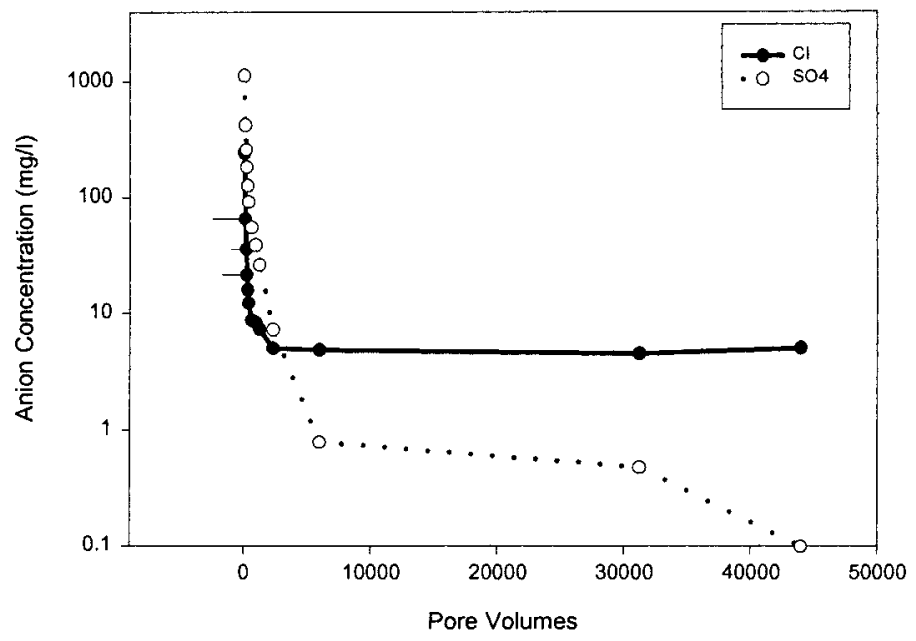

b

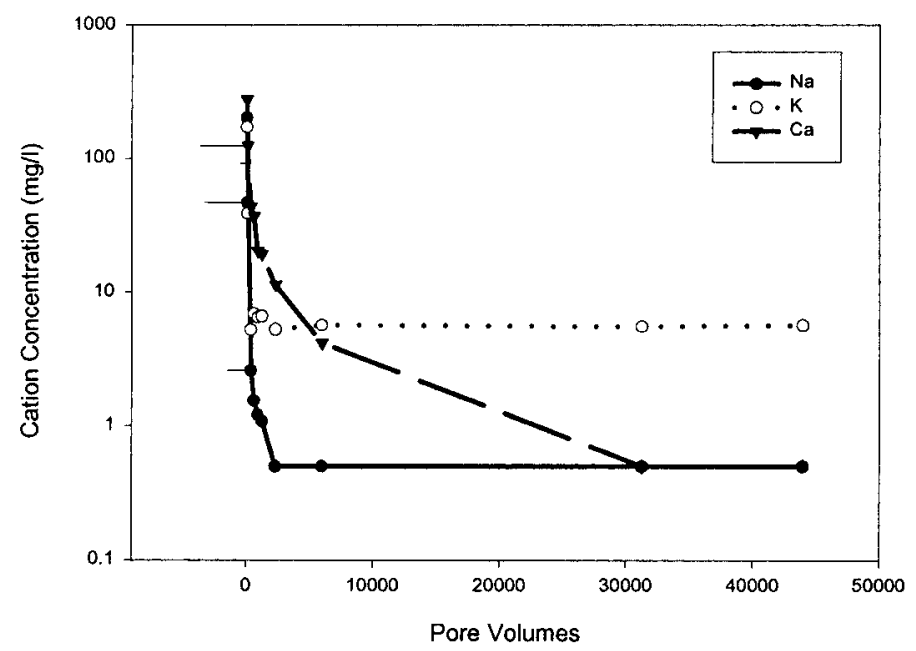

c

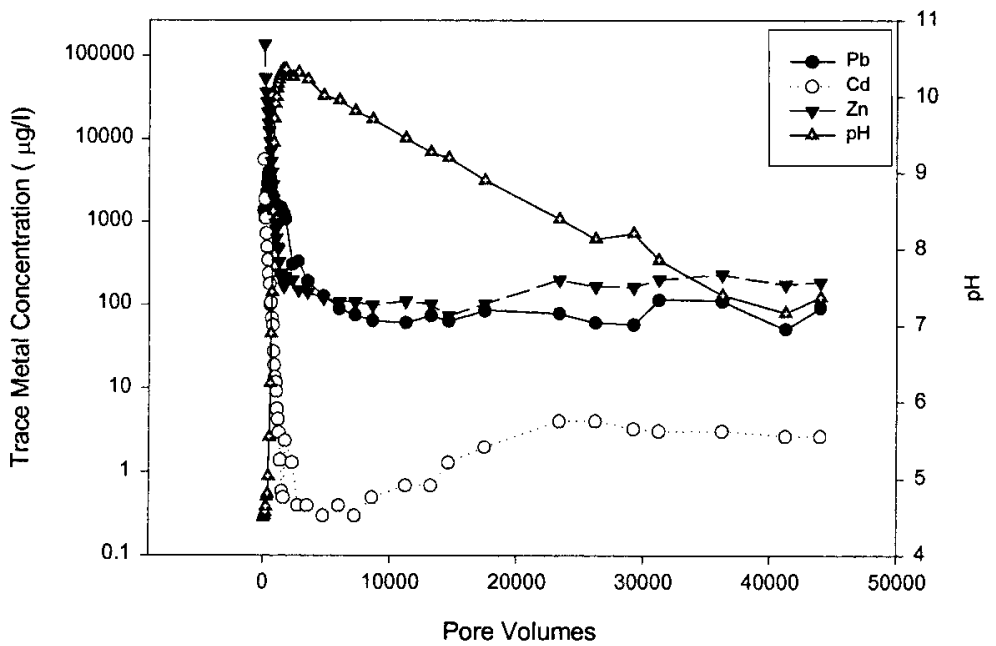

Figure 1. Concentration of (a) major anions, (b) major cations, and (c) trace metals and $\mathrm{pH}$ in column effluent. Ash 5F, flow rate $=2.0 \mathrm{~mL} / \mathrm{min}$. 
$\mathbf{a}$

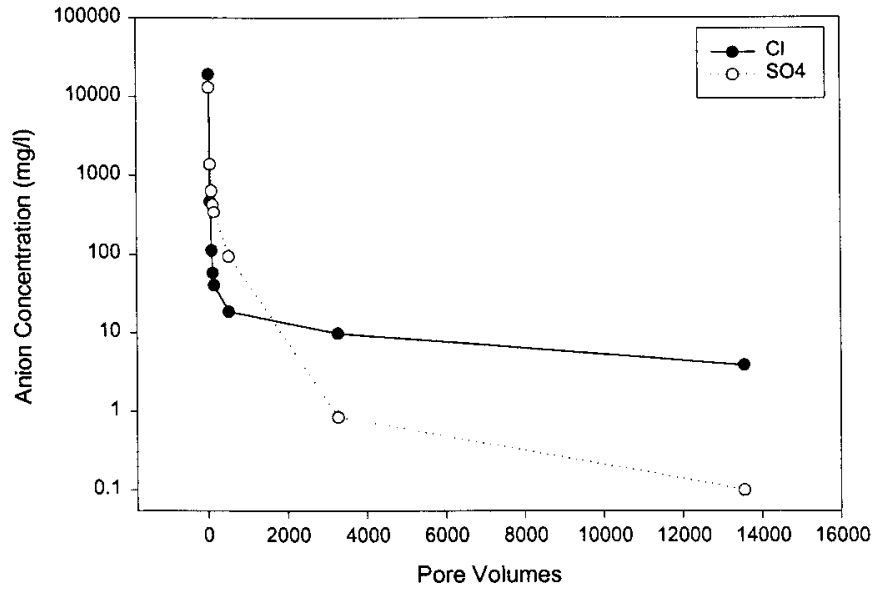

b
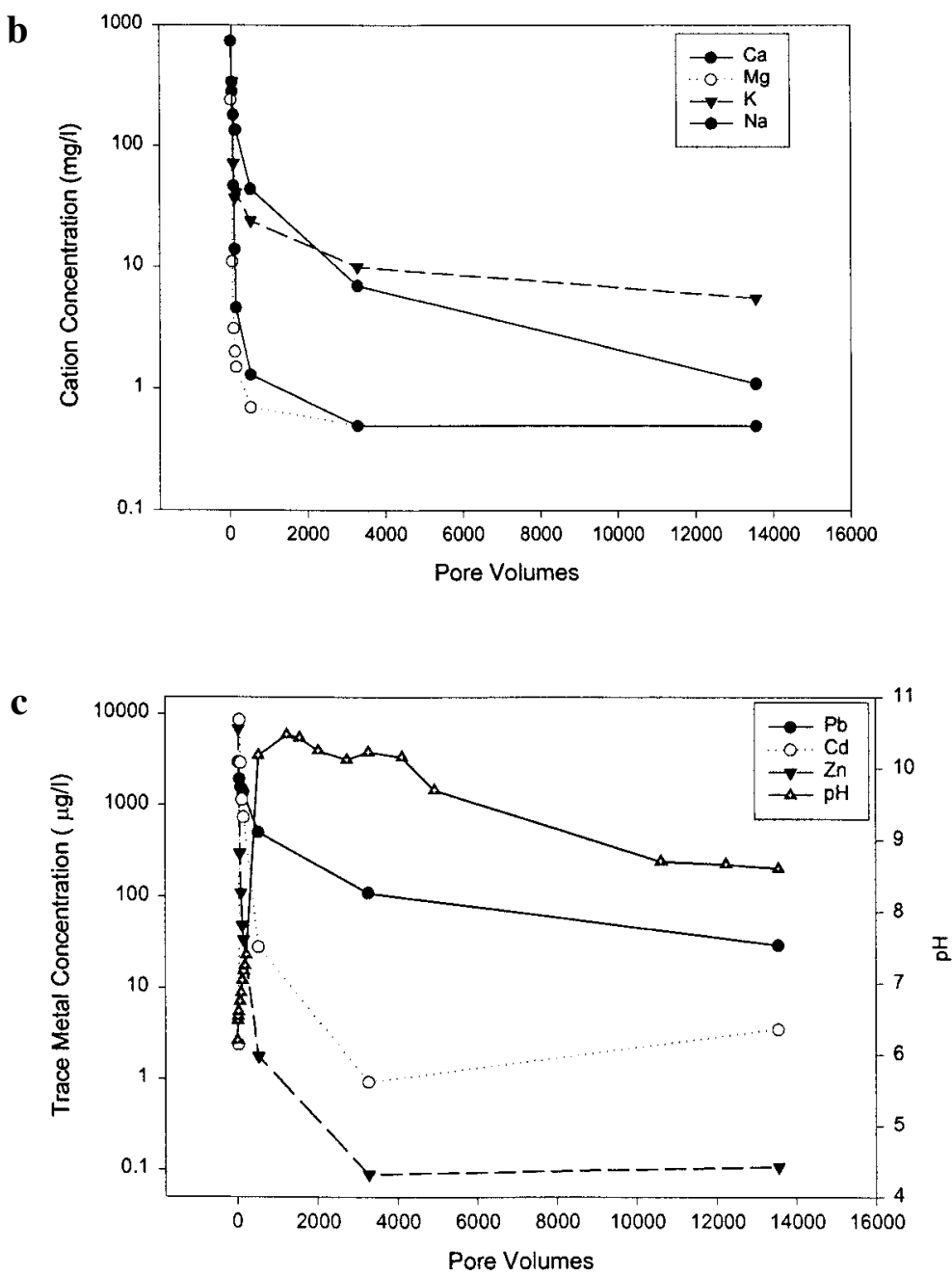

Figure 2. Concentration of (a) major anions, (b) major cations, and (c) trace metals and pH in column effluent. Ash 5F, flow rate $=0.5 \mathrm{~mL} / \mathrm{min}$. 
a

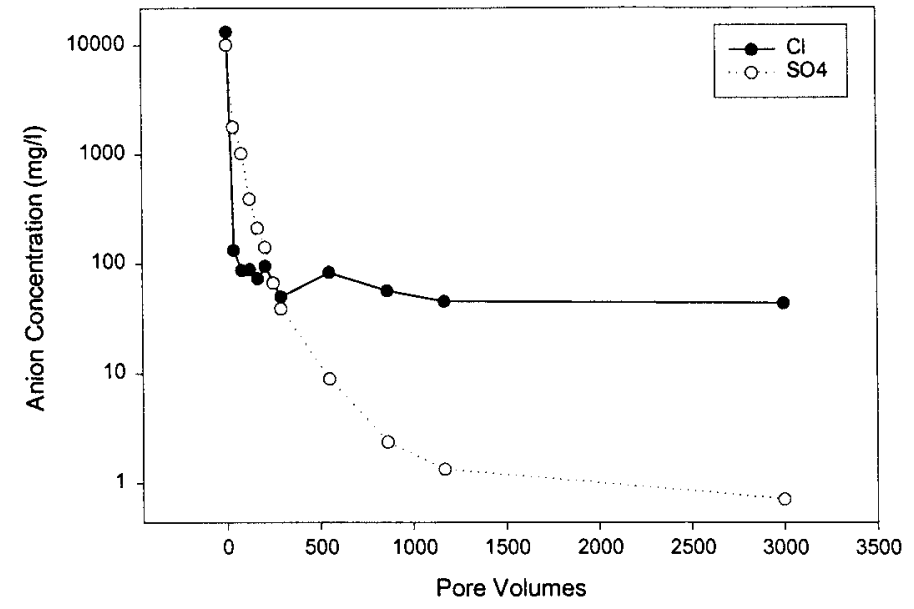

b

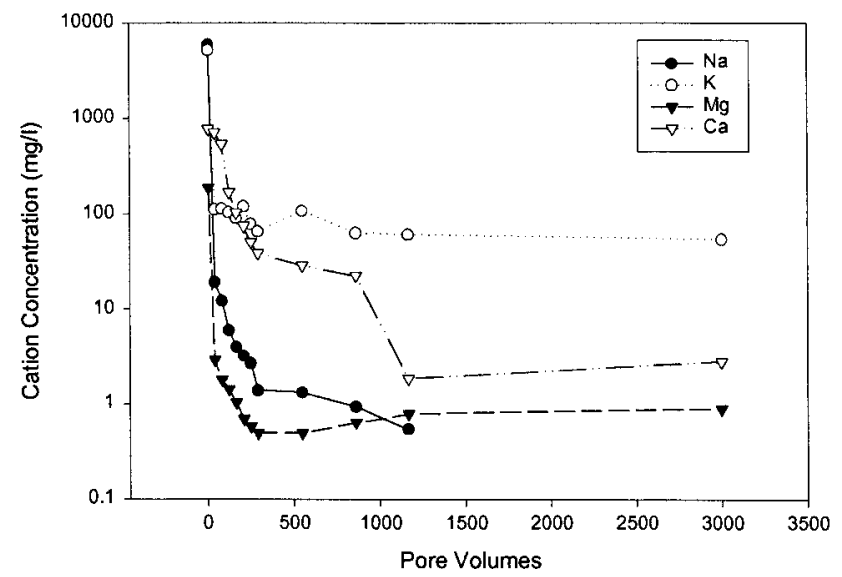

C

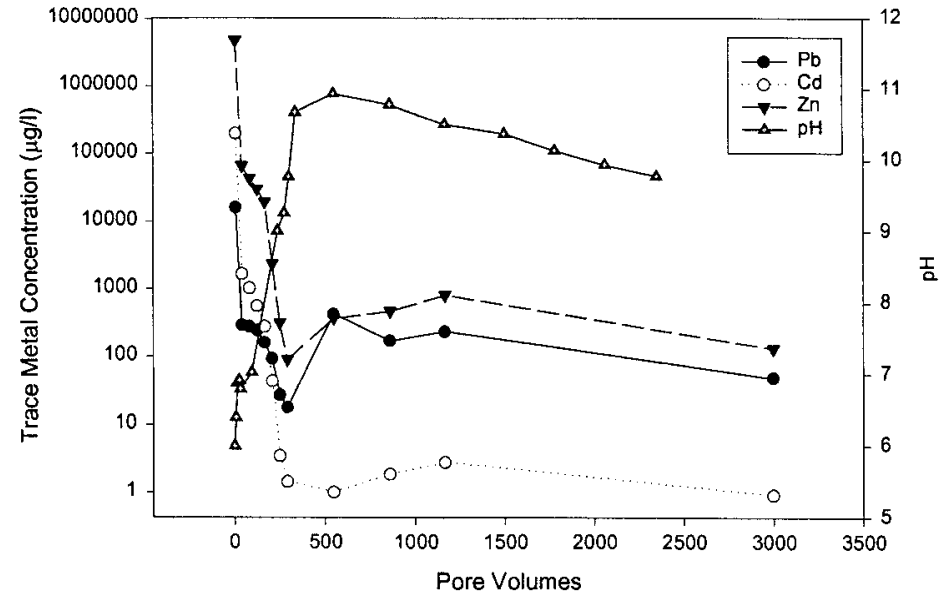

Figure 3. Concentration of (a) major anions, (b) major cations, and (c) trace metals and pH in column effluent. Ash 5F, flow rate $=0.1 \mathrm{~mL} / \mathrm{min}$. 

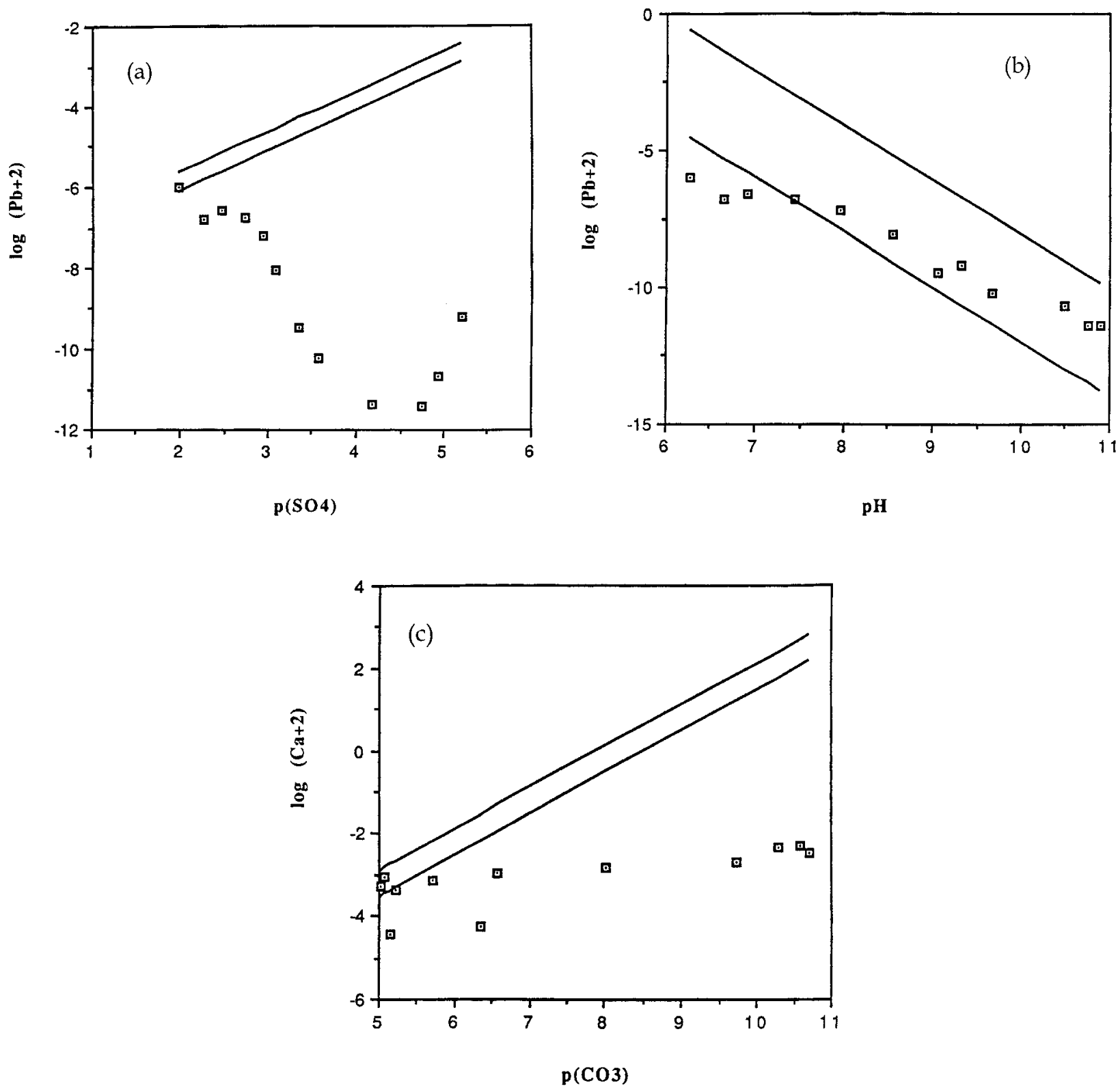

Figure 4. Lead activity vs. (a) $\mathrm{SO}_{4}{ }^{-2}$ activity and (b) $\mathrm{pH}$, and (c) calcium activity vs. $\mathrm{CO}_{3}{ }^{-2}$ activity. Lines represent the solubility of (a) $\mathrm{PbSO}_{4}$, (b) $\mathrm{Pb}(\mathrm{OH})_{2}$, and (c) $\mathrm{CaCO}_{3}$ based on the range of $\mathrm{K}_{\mathrm{so}}$ values found in the literature.

type behavior, but decreases in response to an increase in $\mathrm{pH}$ and possibly carbonate activity. As the $\mathrm{pH}$ decreases at later times, the lead activity increases due to both the decrease of carbonate activity and the increased solubility of $\mathrm{Pb}(\mathrm{OH})_{2(\mathrm{~s})}$.

The concentrations of two of the major ions, calcium and sulfate, also appear to be controlled by the solubilities of solid phases. It appears that at early times $\mathrm{CaSO}_{4(\mathrm{~s})}$ controls the activity of the ions in solution, and at later times and higher $\mathrm{pH}$ values, $\mathrm{CaCO}_{3(\mathrm{~s})}$ may control $\mathrm{Ca}$ activity, as shown in Fig. 4(c). This may be the reason that calcium and sulfate do not exhibit the same mass transfer effects as observed with the other major ions.

Figure 5 shows the mass of lead released per gram of ash per liter of leachant (or $\mu \mathrm{g} / \mathrm{L}$ per $\mathrm{g}$ of ash), and demonstrates significantly higher concentrations of lead released as flow rate is increased. Two factors are at work here: the chemical environment is changed because both peak $\mathrm{pH}$ and sulfate concentration decrease as flow rate increases (allowing greater concentrations of $\mathrm{Pb}^{+2}$ into solution). In essence, the variations in flow rate influence the concentrations of mass-transport controlled species in 


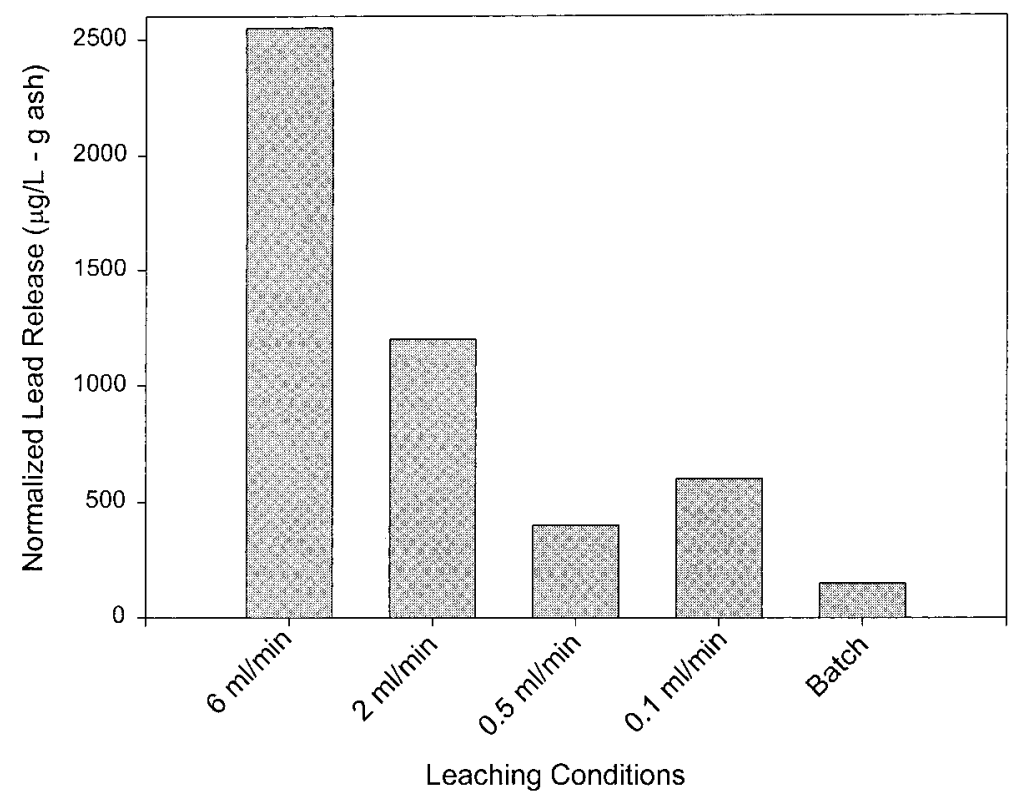

Figure 5. Concentration of lead released per gram of ash under different flow conditions and in batch extraction (L:S $=16: 1$, distilled water extractant, 48-h extraction time).

the leachate, which in turn, influence the release of solubility-controlled species. The physical environment is also changed as boundary layer mass transfer resistance is lower at higher flow rates. It should be noted that the fluxes shown in Fig. 5 are averaged over the entire column experiment, which may give results differing from instantaneous fluxes calculated at a given point in time.

\section{MODELING APPROACH}

It is clear that a satisfactory description of leachate composition must involve interactions among several chemical components that produce a variety of chemical species ranging from discrete precipitates, as indicated above, to soluble complexes, which comprise the total soluble concentration of a given chemical component. In addition, the advective and diffusive transport of components in the system must be considered in cases where chemical equilibrium reactions do not control solute concentrations. The general balance equation on each component, for one-dimensional nondispersive transport through a homogeneous medium, is given by

$$
\begin{aligned}
\frac{\partial u_{i}}{\partial t}+\sum_{j=1}^{N_{p}} A_{i j} \frac{\partial P_{j}}{\partial t}=-\nu \frac{\partial u_{i}}{\partial x} & +\frac{\partial C_{s i}}{\partial t}\left(\frac{1-\varepsilon}{\varepsilon}\right) \\
& +\frac{\partial \bar{C}_{p i}}{\partial t} \quad i=1, N_{c}
\end{aligned}
$$

where $u_{i}$ is the total soluble (and therefore mobile) concentration of component $i[\mathrm{M}], P_{j}$ is the total concentration of precipitate $j$ containing component $i$ with a stoichiometry of A [M], $C_{s i}$ is the concentration of available (for release) component $i$ on the ash solid surface [M], $\bar{C}_{p i}$ is the average concentration of component $i$ in the interior matrix of the ash (available for diffusive flux) [M], $\varepsilon$ is the ash bed porosity (unitless), $\nu$ is the interstitial velocity $[\mathrm{cm} / \mathrm{s}]$, and $N_{c}$ and $N_{p}$ are the number of components and precipitates, respectively. Additional balances for $C_{s}$ and $\bar{C}_{p}$ on and within the ash particles are given by

$$
\frac{\partial C_{s i}}{\partial t}=a k_{c i}\left(C_{s i}-u_{i}\right) \quad i=1, N_{c}
$$

and

$$
\frac{\partial \bar{C}_{p i}}{\partial t}=\frac{\pi^{2} D_{e i}}{R_{p}^{2}}\left(\bar{C}_{p i}-u_{i}\right) \quad i=1, N_{c}
$$

where $a$ is the area to volume ratio of the ash particle $\left[\mathrm{cm}^{-1}\right], R_{p}$ is the average radius of the ash particles [cm], $k_{c}$ is the mass transfer coefficient for surface layer release $[\mathrm{cm} / \mathrm{s}]$, and $D_{e}$ is the effective diffusion coefficient for transport from the interior of the ash particles $\left[\mathrm{cm}^{2} / \mathrm{s}\right]$.

The final equations for the model are the chemical mass action constraints with the functionality appropriate for the interactions of interest; for precipitates, for example, the general solubility product would be

$$
K_{j}^{s o}=\left[F\left(u_{1}, \ldots u_{N_{c}}, A_{i j}\right)\right] \quad i=1, N_{c} \quad j=1, N_{p} .
$$

The $\mathrm{pH}$ values measured during experiments were input to the governing solubility equations as part of the simulation.

It should be stressed at this point that the form of Equation (4) will depend on the nature of the chemical inter- 
actions to be described. Thus, if sorptive controls on solubility are perceived to be of importance (as appears often to be the case, for example, for leachates from bottom ashes), then the proper functional form for (4) would be used (Theis and Wirth, 1977; Van der Hoek and Comans, 1996). Indeed, for the strong base cations $\mathrm{Na}^{+}$and $\mathrm{K}^{+}$, and also the anion $\mathrm{Cl}^{-}$, chemical solubility controls do not seem to be important, and their appearance in leachate is governed by mass transfer considerations alone.
The formulation of the problem is completed by stating the auxiliary conditions. Because the model will be applied to existing one-dimensional leachate data obtained in the laboratory, the most appropriate conditions on $u$ and $P$ are

$$
\begin{aligned}
& u_{i}(x, 0)=0 \\
& u_{i}(0, t)=0
\end{aligned}
$$
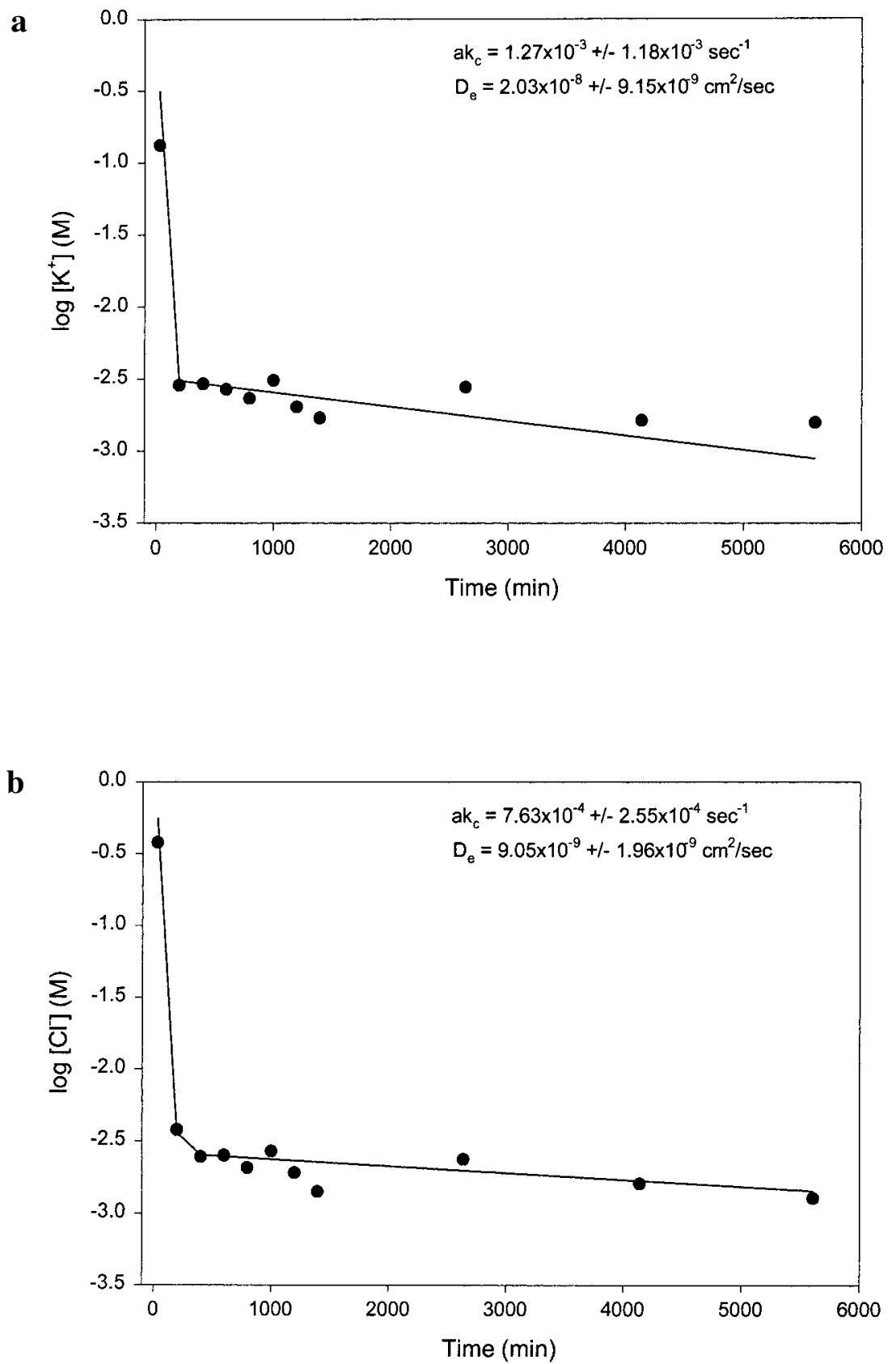

Figure 6. Experimental data and model simulation of (a) potassium, and (b) chloride concentration in leachate. Best-fit parameter estimates with $95 \%$ confidence intervals shown on figure. 


$$
\begin{aligned}
& P_{j}(x, 0)=0 \quad j=1, N_{p} \\
& P_{j}(0, t)=0 \quad j=1, N_{p}
\end{aligned}
$$

Initial conditions for $C_{s}$ and $\bar{C}_{p}$ are somewhat more problematic because it is difficult to obtain a priori information on the releasable concentrations of components. Batch leachate or total content data may not accurately reflect the initial values because the measurements are generated under less than realistic conditions, as demonstrated in Fig. 5. As indicated previously, the approach employed in this study was to use the integrated column leachate val- ues (i.e., the total mass released during the column experiment) as a first approximation, that is

$$
C_{\mathrm{si} 0} \geq \frac{1}{V_{s}} \int_{0}^{t_{b}} q \cdot u_{t i} d t \quad i=1, N_{c}
$$

and

$$
\bar{C}_{\mathrm{pi} 0} \geq \frac{1}{V_{s}} \int_{t_{b}}^{t} q \cdot u_{t i} d t \quad i=1, N_{c}
$$

where $u_{t i}$ is the experimental minicolumn leaching curve for component $i[\mathrm{M}], q$ is the flow rate $\left[\mathrm{cm}^{3} / \mathrm{s}\right]$, and $V_{s}$ is the volume of ash $\left[\mathrm{cm}^{3}\right]$. The point $\mathrm{b}$ corresponds to
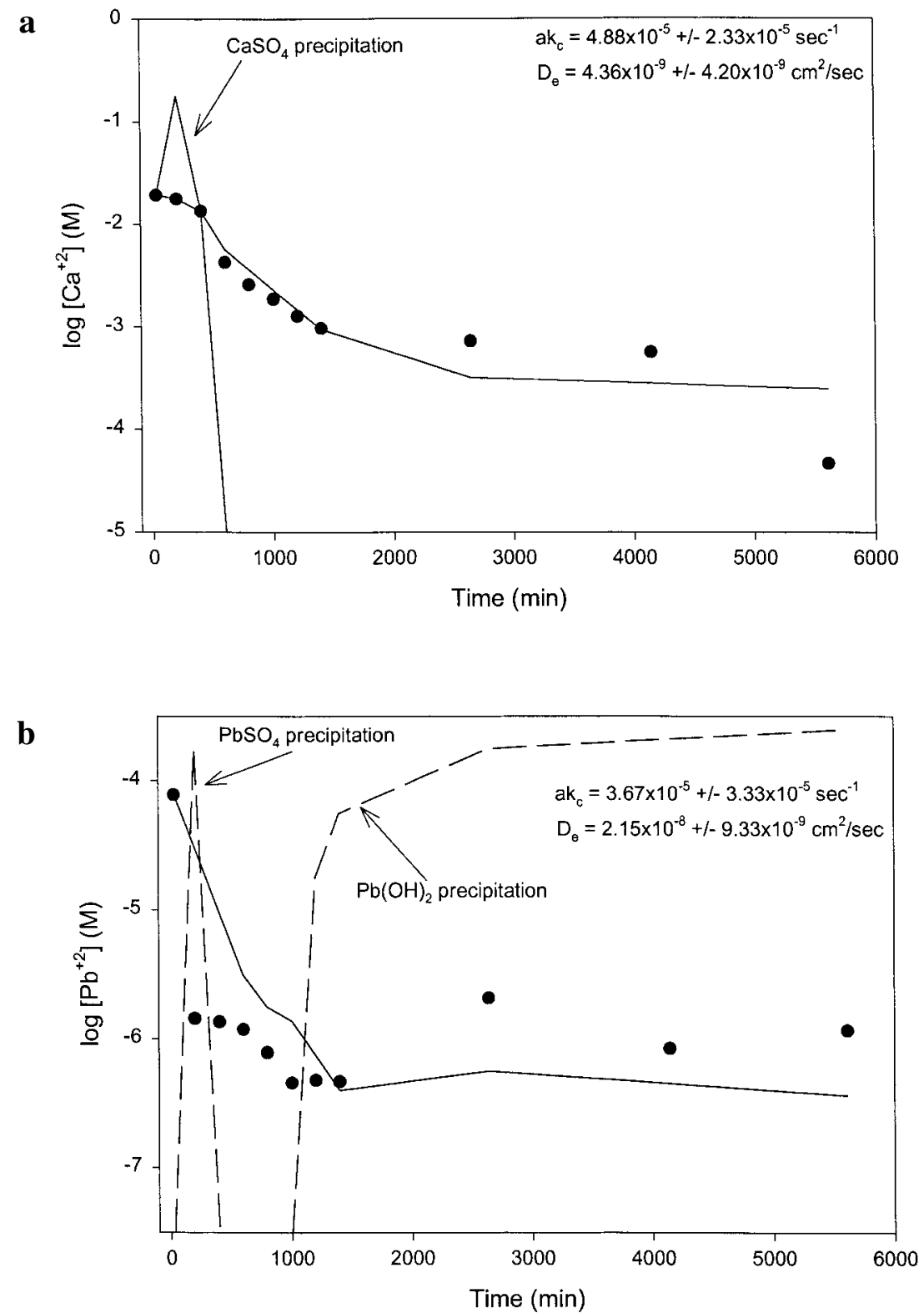

Figure 7. Experimental data and model simulation of (a) calcium, and (b) lead concentration in leachate. Best-fit parameter estimates with $95 \%$ confidence intervals shown on figure. 
the point of transition between surface mass transfer and diffusive release of material, and is estimated by inspection of the curve.

\section{MODELING RESULTS AND DISCUSSION}

As discussed above, it appears that various discrete precipitates control the concentration of several ionic species in the ash leachate; thus, the solubility products given in Equation (4) are considered to be known and the parameters to be estimated are the mass transfer and effective diffusion coefficients for each component. In all, seven components were included in this analysis: $\mathrm{Na}, \mathrm{K}$, $\mathrm{Ca}, \mathrm{Mg}, \mathrm{SO}_{4}, \mathrm{Cl}$, and $\mathrm{Pb}$. The procedure used was to discretize Equations (1) through (4) and numerically approximate the solution using a Lax-Wendroff finite difference scheme (Press et al., 1992). This solution algorithm is imbedded within a numerical parameter estimation procedure based upon the technique of Levenberg and Marquardt (Marquardt, 1963). Thus, Equations (1) through (4) are solved with an initial set of values (in this case guessed values of $a k_{c}$ and $D_{e}$ ), and the solution is compared with the experimental values using the sum of squared differences. The Levenberg-Marquardt method then governs the iteration to the point in parameter space corresponding to the minimum sum of squared differences. In the process, sufficient information is gen- erated to produce the approximate $95 \%$ joint confidence intervals for both parameters.

The results of the computation are presented in Figs. 6 and 7, in which the model output is shown with experimental data. Also shown are the estimates for $a k_{c}$ and $D_{e}$ along with error bounds (these error bounds represent the major axes of the joint $95 \%$ confidence region for the two-parameter set). Figure 6(a) and (b) for potassium and chloride, respectively, illustrate the behavior of components that exhibit essentially conservative behavior. Aside from participation in the formation of ion pairs, the rate of release of these components is controlled by surface and diffusive mass transport. The rapid dropoff in concentration and transition between these two phenomena can be clearly distinguished in the figures.

Figure 7(a) shows the model predictions for the release of calcium from the ash matrix as well as the two estimated mass transfer coefficients. The simulation predicts the formation of calcium sulfate, which limits the release of calcium in the early stages of leaching (for the first 500 pore volumes or so). The mass transfer coefficients are also lower than observed for conservative components indicating that sorption may be an important consideration in the release rates of some solutes.

Figure 7(b) shows predicted lead release rates and those observed in the dynamic leaching experiment. As demonstrated above with calcium, discrete precipitates are predicted to form. In this case, however, lead sulfate

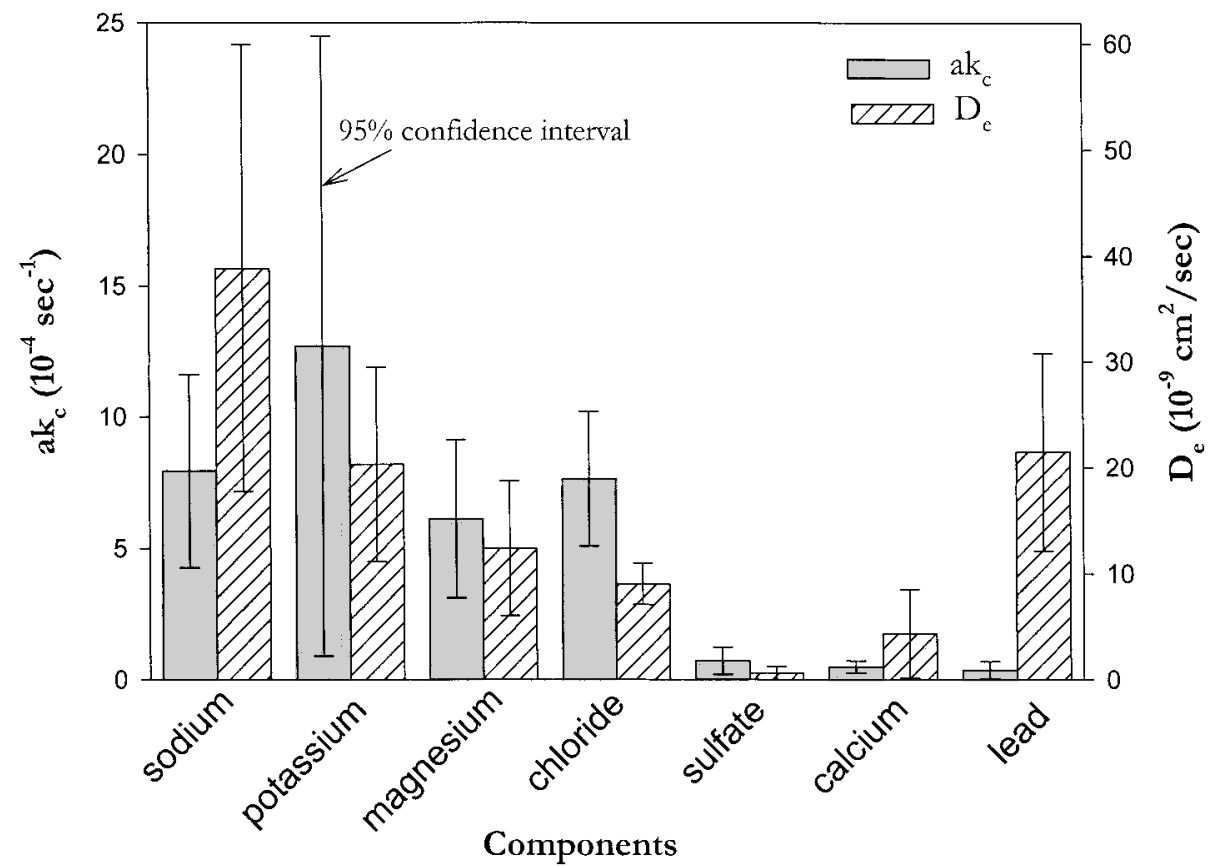

Figure 8. Estimates of mass transfer coefficients for all seven components investigated with approximate $95 \%$ confidence intervals. 
limits lead solubility early in the leaching process, while lead hydroxide limits its concentration in solution at later times when there is an increase in $\mathrm{pH}$ and a decline in sulfate concentrations. This transition was suggested by the thermodynamic speciation calculations discussed above and illustrated in Fig. 4.

Figure 8 summarizes the results of the parameter estimation exercise for all seven solutes investigated along with the $95 \%$ joint confidence intervals for each estimate. Both mass transfer and effective diffusion coefficients for $\mathrm{Ca}, \mathrm{SO}_{4}$, and $\mathrm{Pb}$ are generally one to two orders of magnitude lower than corresponding values for the conservative components with the exception of the effective diffusion coefficient for lead. In general, lower estimates are expected because of the retardation caused by chemical interactions within the ash matrix and on the ash surface (Van der Hoek and Comans, 1996; Meima and Comans, 1998). It is unclear why the effective diffusion coefficient estimated for lead release does not follow this trend. One hypothesis is that the solubility controls on lead, for example, by lead sulfate early in the leaching process, is a result of precipitate formation in the interstices of the packed bed, that is, lead is leached from its respective parent compound, and subsequently forms lead hydroxide. This phenomena was observed at the highest flow rate experiment $(6.0 \mathrm{~mL} / \mathrm{min})$, in which a lead precipitate was formed after exiting the column reactor (i.e., the formation of the precipitate was not rapid enough and the solution exited the packed bed supersaturated). Thus, the formation of lead precipitates in the pores of the ash bed may result in a readily available deposit, which in turn, may result in the higher estimates for the effective diffusion coefficient of lead.

\section{ACKNOWLEDGMENTS}

This research was supported by grant \#15332-4890 from the New York State Combustion Research Institute. The authors express their appreciation to Dr. Richard E. Schuler, Director. In addition, the authors thank Ms. Eleanor Hopke, who assisted with analytical measurements.

\section{REFERENCES}

BUCHHOLZ, B.A., and LANDSBERGER, S. (1995). Leaching dynamics studies of municipal solid waste incinerator ash. J. Air Waste Manage. Assoc. 45, 579-590.

CHANDLER, A.J., EIGHMY, T.T., HARTLEN, J., HJELMAR, O., KOSSON, D.S., SAWELL, S.E., VAN DER SLOOT, H.A., and VEHLOW, J. (1997). Municipal Solid Waste Incinerator Residues, Studies in Environmental Science 67. New York: Elsevier.
CHICHESTER, D.L., and LANDSBERGER, S. (1996). Determination of leaching dynamics of metals from municipal solid waste incinerator fly ash using a column test. J. Air Waste Manage. Assoc. 46, 643-649.

FRUCHTER, J.S., RAI, D., and ZACHARA, J.M. (1990). Identification of solubility-controling solid phases in a large fly ash field lysimeter. Environ. Sci. Technol. 24, 1173-1179.

GARDNER, K.H. (1991). Characterization of leachates from municipal incinerator ash materials. Report 91-8, Clarkson University.

KOSSON, D.S., VAN DER SLOOT, H.A., and EIGHMY, T.T. (1996). An approach for estimation of contaminant release during utilization and disposal of municipal waste combustion residues. J. Hazrad. Mater. 47, 43-75.

MARQUARDT, D.W. (1963). An algorithm for least-squares estimation of nonlinear parameters. J. Soc. Indust. Appl. Math. 11, 431-441.

MEIMA, J.A., VAN ZOMEREN, A., and COMANS, R.N.J. (1999). Complexation of $\mathrm{Cu}$ with dissolved organic matter in municipal solid waste incinerator bottom ash leachates. Environ. Sci. Technol. 33(9), 1424-1429.

MEIMA, J.A., and COMANS, R.N.J. (1998). Application of surface complexation/precipitation modeling to contaminant leaching from weathered municipal solid waste incinerator bottom ash. Environ. Sci. Technol. 32(5), 688-693.

NATIONAL INSTITUTE OF STANDARDS AND TECHNOLOGY (NIST). (1995). Standard Reference Database 46 (Critically Selected Stability Constants of Metal Complexes Database). Gaithersburg, MD: U.S. Dept. of Commerce.

PAPELIS, C., HAYES, K.F., and LECKIE, J.O. (1998). Hydraql: A Program for the Computation of Chemical Equilibrium Composition of Aqueous Batch Systems Including Surface Complexation Modelling of Ion Adsorption at the Oxide/Solution Interface. Technical report No. 306. Department of Civil Engineering, Stanford University, Palo Alto, CA.

PRESS, W.H., TEUKOLSKY, S.A., VETTERLING, W.T., and FLANNERY, B.P. (1992). Numerical Recipes in Fortran: The Art of Scientific Computing, 2nd ed. New York: Cambridge University Press.

THEIS, T.L., and WIRTH, J.L. (1977). Sorptive behavior of trace metals on fly ash in aqueous systems. Environ. Sci. Technol. 11, 1096.

USEPA. (1998). Characterization of Municipal Solid Waste in the United States: 1997 Update. Municipal and Industrial Solid Waste Division, Office of Solid Waste, Report No. EPA530-R-98-007.

VAN DER HOEK, and COMANS, R.N.J. (1996). Modeling arsenic and selenium leaching from acidic fly ash by sorption on iron (hydr)oxide in the fly ash matrix. Environ. Sci. Technol. 30(2), 517-523.

WILES, C., and SHEPHERD, P. (1999). Beneficial Use and Recycling of Municipal Waste Combustion Residues-A Comprehensive Resource Document, NREL/BK-570-25841. Golden, OH: National Renewable Energy Laboratory. 